\title{
Antioxidative assessment of new trans-palladium (II) complexes in head and neck cancer
}

Authors' Contribution:

A-Study Design

B-Data Collection

C-Statistical Analysis

D-Data Interpretation

E-Manuscript Preparation

F-Literature Search

G-Funds Collection

\author{
Katarzyna Malinowska' ${ }^{1,3 E B}$, Dariusz Kaczmarczyk ${ }^{2 F}$, Radosław Zajde ${ }^{3 C}$, Anna Merecz-Sadowska ${ }^{3 F}$, \\ Jurek Olszewski ${ }^{\mathrm{AD}}$, Małgorzata Majczyk ${ }^{6 \mathrm{C}}$, Alicja Nowak-Zduńczyk ${ }^{5 \mathrm{D}}$, Hanna Zielińska-Bliźniewska ${ }^{1,4 A}$ \\ 'Department of Allergology and Respiratory Rehabilitation, 2nd Chair of Otolaryngology, Medical University of Lodz, Lodz, Poland \\ 2Department of Head and Neck Neoplasms Surgery, Medical University of Lodz, Lodz, Poland \\ ${ }^{3}$ Chair of Business Informatics, University of Lodz, Lodz, Poland \\ ${ }^{4}$ Department of Otolaryngology and Laryngological Oncology, Audiology and Phoniatrics II Chair of Otolaryngology, Medical University in \\ Lodz, Poland \\ ${ }^{5}$ University of Business and Health Sciences in Lodz, Poland \\ ${ }^{6}$ Department of Human Physiology, Medical University of Lodz, Lodz, Poland
}

Article history: Received: 23.06.2019 Accepted: 29.07.2019 Published: 02.08.2019

ABSTRACT:

Background: Head and neck neoplasms stand for $6 \%$ of all malignant neoplasms worldwide. Chemotherapy has limited use due to the biological properties of the tumor (in the majority of cases moderately and poorly differentiated squamous cell carcinoma). The fundamental molecule used in treatment is cisplatin and its derivates, that can be associated with fluorouracil. The new chemotherapeutic agents are not in common use during the treatment of head and neck malignancies. However, the use of low molecular weight complexes Pd (II) carries the potential of being more effective in therapy.

Material and Methods: Fifty-one patients, 30 men and 21 women (aged $52.9 \pm 12.1$ years) with head and neck cancer were included in the study. Fifty-one healthy subjects, 31 men and 20 women, (aged $54.1 \pm 14.7$ years) years formed the control group. Antioxidant enzymes, superoxide dismutase, and catalase activities in erythrocytes were examined.

Results: An increased level of antioxidant enzymes was seen in the blood samples from patients with head and neck cancer after incubation with Pd (II) complex. In the group we obtained a statistically significant result $\mathrm{p}=<0.001$.

Discussion: That project may contribute to the development of new, more efficient head and neck cancer treatment strategies. In our opinion, the results can be used in the future to develop a valuable prognostic marker of the disease. This is important because the initial phase of cancer is asymptomatic. The search for factors involved in pathogenesis translates into economic benefits and makes therapy more effectiveness through the reduction of treatment expenses.

KEYWORDS: $\quad$ antioxidant enzymes, head and neck cancer, oxidative stress, Pd (II) complexes, reactive oxygen species

\section{INTRODUCTION}

Cisplatin, or cis-diamminedichloroplatinum (II) is a valuable antitumor drug that causes transcriptional and translational impairment by binding to DNA and affects the cell cycle and apoptosis $[1,2]$. However, it is not ideal despite the drug resistance which was assumed to reduce its effectiveness [3, 4]. Moreover, it has been proved that cisplatin causes hematologic toxicity entailing oxidative stress, which manifests itself as a defect in the biological function of blood cells $[5,6]$. It also has several disadvantages including side effects such as nephrotoxicity, ototoxicity, neurotoxicity, myelotoxicity, peripheral neuropathy and hematological toxicity $[5,7,8]$. Monitoring the adverse effects of cisplatin cancer chemotherapy in patients has generated the creation of new areas of research mainly focused on attempts to find new non-platinum metal-based complexes displaying low toxicity with improved therapeutic properties [3, 9]. Although palladium (II) complexes are much more labile than corresponding platinum (II) complexes, the lability of central palladium (II) may be much lower because of the shielding effect [10]. Pd (II) ions can interact with DNA thus enabling cross bindings and inhibiting its synthesis as well as inducing apoptosis [11-14].

Coordination chemistry concerns the search for novel compounds to act as good complexing agents with transition metal ions. One such group of compounds includes the azole heterocycles represented by pyrazole and its derivatives.

Pyrazoles are organic compounds whose molecules contain a fivemembered ring with two nitrogen atoms in positions 1, 2. Pyrazoles show weak acidic and alkaline properties. Their acidic properties arise from the possibility of detaching a proton from the nitrogen atom N1 in a strongly alkaline environment. The basic properties are associated with the presence of a non-binding electron pair 
Tab. I. Effects of complex Pd (II) (a), (b) and (c) on the activity of CAT and SOD enzymes in HNSCC patients (group A1 compared to group A2).

\begin{tabular}{|c|c|c|c|}
\hline \multicolumn{4}{|c|}{ STUDY GROUP A-HNSCC PATIENTS } \\
\hline ENZYMES & A1 - GROUP EXPOSURE TO PD (II) COMPLEXES N = 51 & A2 - GROUP DOES NOT HAVE EXPOSURE TO PD (II) COMPLEXES N = 51 & PVALUE \\
\hline \multicolumn{4}{|l|}{ Complex Pd (II) (a) } \\
\hline CAT [BU/g Hb] & $15.24 \pm 5.93$ & $14.14 \pm 4.77$ & 0.30 \\
\hline ZnCu SOD [U/g Hb/10oml] & $2192.08 \pm 889.46$ & $1486.36 \pm 813,53$ & $<0.001$ \\
\hline \multicolumn{4}{|l|}{ Complex Pd (II) (b) } \\
\hline CAT [BU/g Hb] & $21.68 \pm 17.30$ & $19.35 \pm 17.30$ & 0.50 \\
\hline ZnCu SOD [U/g Hb/10oml] & $2600.41 \pm 643.29$ & $1752.02 \pm 811.05$ & $<0.001$ \\
\hline \multicolumn{4}{|l|}{ Complex Pd (II) (c) } \\
\hline CAT $[\mathrm{BU} / \mathrm{g} \mathrm{Hb}]$ & $21.66 \pm 6.19$ & $15.75 \pm 5.26$ & $<0.001$ \\
\hline ZnCu SOD [U/g Hb/10oml] & $2423.28 \pm 832.84$ & $2348.58 \pm 720.04$ & 0.63 \\
\hline
\end{tabular}

on the nitrogen atom. Pyrazol readily forms complexes with metal ions due to the presence of a free electron pair on the N2 nitrogen atom. The nature of the metal ion and the proteolytic properties of pyrazoles determine the composition, structure and durability of the coordination bonds $[15,16]$.

Recently published reports have described other systems for the synthesis of azole complexes with platinum (II), palladium (II), ruthenium (III) and copper (II) which demonstrate antitumor and antioxidant properties. The study has examined the relationship between the pharmacological action and chemical structure of the pyrazole derivatives used in medicine $[17,18]$. An essential element of the pharmacological action is the presence of substituents in the nitrogen atoms in the ring. Most pyrazolone derivatives with 1 -phenyl substituents are non-steroidal analgesics. Compounds with a methyl group at position 2 or 3 also have beneficial pharmacological effects, and their action can be enhanced by replacing the groups with branched alkyl substituents. Removing the substituents from the nitrogen atoms effectively inactivates the drug.

This paper examines the impact of newly synthesized complex compounds of palladium (II) on the antioxidant barrier system. The biological importance of metal systems with pyrrole ligands has aroused interest in their properties, and numerous studies have examined the relationship between their structure and biological activity.

The discovery of new drugs follows the process of structural changes to design a compound with a modifying function [19]. Although knowledge of the chemical structure of a certain compound in a complex can help scientists predict the toxicity of similar substances, even a small structural change may considerably affect physicochemical properties and biological activity of the compound. Moreover, the toxicity of the original substance can be reduced or even eliminated by adding substituents. For instance, although the 2-aminoimidazole core itself does not exhibit antitumor activity, introducing an imino compound into the system will provide it with biological activity. Many new anticancer compounds have been obtained by making small changes to the existing models, for example, transition metal ion complexes. Fortunately, the identification of biologically active compounds has been made more effective with the computer-aided drug design, development of new methods for the synthesis and separation of compounds, as well as a range of biochemical techniques [20-24].

\section{MATERIALS AND METHODS}

\section{Patients}

Fifty-one patients with head and neck cancer (group A) with M0 (no distant metastasis) status, 30 men and 21 women with a mean age of $52.9 \pm 12.1$ years were enrolled in this study. The main group was subdivided into two subgroups: A1 (in vitro incubation of complexes with blood sample) and A2 (no incubation of complexes with blood sample). The control group (group B) included 51 subjects, 31 men and 20 women with a mean age of $54.1 \pm 14.7$ years with no symptoms of head and neck cancer. The clinical examination was performed during cervical and supraclavicular palpation of the lymph nodes and endoscopic screening. The group was also subdivided into subgroups B1 (in vitro incubation of complexes with blood sample) and B2 (no incubation of complexes with blood sample). All the patients and controls were matched for age and gender. All the patients from the test group were admitted to the Department of Head and Neck Neoplasms Surgery, Medical University of Lodz. All patients signed an informed consent to participate in the study. The studies were carried out in compliance with the Declaration of Helsinki. The study was conducted with permission no. RNN/142/09/KB given by the Bioethics Committee of the Medical University of Lodz, Poland.

\section{Materials}

The study material included about $5 \mathrm{ml}$ of peripheral blood obtained from the patients of the Department of Head and Neck Neoplasms Surgery, Medical University of Lodz, Poland. Before sample collection each patient was explained the purpose of the procedure and an informed consent was obtained from them.

\section{Synthesis of complexes}

Pyrazole (a), 3-methylpyrazole (b) and 3,5-dimethylpyrazole (c) with palladium (II) were synthesized.

The reaction was carried out at room temperature. 0.015 mole of the corresponding pyrazole: $\mathrm{a}, \mathrm{b}, \mathrm{c}$ was dissolved in $1 \mathrm{ml}$ of water in a $10 \mathrm{ml}$ round-bottomed flask and then dripped into the previously prepared solution of $0.0075 \mathrm{~mol}$ of dipotassium tetrachloropalladium (II) in $2 \mathrm{ml}$ of water. Samples were intensively mixed. 
Tab. II. Effects of complex Pd (II) (a), (b) and (c) on the activity of CAT, SOD in the control groups (group B1 compared to group B2).

\begin{tabular}{|c|c|c|c|}
\hline \multicolumn{4}{|c|}{ CONTROL GROUP (B) } \\
\hline ENZYMES & B1-GROUP EXPOSURE TO PD (II) COMPLEXES N = 51 & B2 - GROUP DOES NOT HAVE EXPOSURE TO PD (II) COMPLEXES N = 51 & PVALUE \\
\hline \multicolumn{4}{|l|}{ Complex Pd (II) (a) } \\
\hline CAT [BU/g Hb] & $32.86 \pm 20.70$ & $28.00 \pm 20.71$ & 0.24 \\
\hline ZnCu SOD [U/g Hb/10oml] & $2429.03 \pm 920.10$ & $2201.55 \pm 700.74$ & 0.16 \\
\hline \multicolumn{4}{|l|}{ Complex Pd (II) (b) } \\
\hline CAT [BU/g Hb] & $36.42 \pm 21.59$ & $35.73 \pm 20.86$ & 0.87 \\
\hline ZnCu SOD [U/g Hb/10oml] & $2181.86 \pm 729.56$ & $1768.43 \pm 1011.17$ & 0.02 \\
\hline \multicolumn{4}{|l|}{ Complex Pd (II) (c) } \\
\hline CAT $[\mathrm{BU} / \mathrm{g} \mathrm{Hb}]$ & $38.92 \pm 23.46$ & $20.08 \pm 10.11$ & $<0.001$ \\
\hline ZnCu SOD [U/g Hb/10oml] & $2217.65 \pm 741.34$ & $2161.65 \pm 682.79$ & 0.69 \\
\hline
\end{tabular}

After adding $\mathrm{K}_{2} \mathrm{PdCl}_{4}$ solutions, the reaction was continued for 12 hours or 4 hours, respectively. The reaction product was precipitated from the solution, washed with water and diethyl ether, and then crystallized from water. Then, it was dried in a vacuum desiccator over calcium chloride.

\section{Complexes a}

Dichlorobis (diphenyl pyrazol- $N^{1}$-ilophosphonate- $\kappa N^{2}$ ) palladium (II) (a)

Anal. Calcd. for a $\mathrm{C}_{30} \mathrm{H}_{26} \mathrm{~N}_{4} \mathrm{O}_{6} \mathrm{Cl}_{2} \mathrm{P}_{2} \mathrm{Pd}, 777.83 \mathrm{~g} / \mathrm{mol}, \mathrm{C} 46.32$, $\mathrm{H}$ 3.37, N 7.20, values received: $\mathrm{C} 46.45, \mathrm{H} 3.38$, N 7.52. FTIRIR $\left(\mathrm{KBr}, \mathrm{cm}^{-1}\right) \mathrm{n}: 1641(\mathrm{C}=\mathrm{C}, \mathrm{C}=\mathrm{N}), 1287(\mathrm{P}=\mathrm{O}), 1060$ (POC), $667(\mathrm{~N}-\mathrm{P})$, $734(\mathrm{Pd}-\mathrm{N}), 454(\mathrm{Pd}-\mathrm{Cl}) .{ }^{31} \mathrm{P} \mathrm{NMR}\left(\mathrm{CDCl}_{3}\right) \mathrm{d}:-10.60$.

\section{Complexes b}

Dichlorobis (diphenyl 3-methylpyrazole- $N^{1}$-ilophosphonate- $k N^{2}$ ) palladium (II) (b)

Anal. Calcd. for $\mathrm{b} \mathrm{C}_{32} \mathrm{H}_{30} \mathrm{~N}_{4} \mathrm{O}_{6} \mathrm{Cl}_{2} \mathrm{P}_{2} \mathrm{Pd}, \mathrm{M}=805.89 \mathrm{~g} / \mathrm{mol}$ : C 47.69, $\mathrm{H} 3.75$, N 6.95, values received: $\mathrm{C} 47.33, \mathrm{H} 3.57, \mathrm{~N}$ 6.63. FTIRIR $\left(\mathrm{KBr}, \mathrm{cm}^{-1}\right) \mathrm{n}: 1582(\mathrm{C}=\mathrm{C}, \mathrm{C}=\mathrm{N}), 1289(\mathrm{P}=\mathrm{O}), 1068$ (POC), 620 (N-P), $635(\mathrm{Pd}-\mathrm{N}), 456$ (Pd-Cl). ${ }^{31} \mathrm{P}$ NMR $\left(\mathrm{CDCl}_{3}\right) \mathrm{d}:-10.85$.

\section{Complexes c}

Dichlorobis (diphenyl 3,5-dimethylpyrazole- $N^{1}$-ilophosphonate- $\kappa N^{2}$ ) palladium (II) (c)

Anal. Calcd. for $\mathrm{C} \mathrm{C}_{34} \mathrm{H}_{34} \mathrm{~N}_{4} \mathrm{O}_{6} \mathrm{Cl}_{2} \mathrm{P}_{2} \mathrm{Pd}, 833.99 \mathrm{~g} / \mathrm{mol}$ : C 48.97, $\mathrm{H}$ 4.11, $\mathrm{N}$ 6.72. values received: $\mathrm{C} 48.65, \mathrm{H} 4.30, \mathrm{~N} 6.70$. FTIRIR $\left(\mathrm{KBr}, \mathrm{cm}^{-1}\right)$ n: $1572(\mathrm{C}=\mathrm{C}, \mathrm{C}=\mathrm{N}), 1257(\mathrm{P}=\mathrm{O}), 1075(\mathrm{POC}), 669(\mathrm{~N}-\mathrm{P}), 675(\mathrm{Pd}-\mathrm{N})$, 431 (Pd-Cl). ${ }^{31} \mathrm{P}$ NMR $\left(\mathrm{CDCl}_{3}\right) \mathrm{d}:-10.02$.

\section{Methods}

Blood samples $(5 \mathrm{ml}$ ) for examination of catalase (Catalase, CAT) and superoxide dismutase (Superoxide Dismutase, SOD) for healthy donors and patients were withdrawn into heparinized tubes from a cubital vein. Blood was centrifuged $10 \mathrm{~min}$ at $3.000 \mathrm{rpm}$ in room temperature. The sedimented erythrocytes were washed three times with $0.9 \% \mathrm{NaCl}$ at the same condition as centrifugation. The $920 \mathrm{ml}$ of supernatant were removed, and the red blood cells were then mixed with $80 \mathrm{ml}$ of Pd (II) complex solution. Next it was added to $1 \mathrm{ml}$ of glucose and incubated at $37^{\circ} \mathrm{C}$, after which the hemolysate was prepared and then frozen at $-70^{\circ} \mathrm{C}$. Thus, the prepared hemolysate was used for further experiments. The concentration of compounds a-c in the experiment were $25 \mathrm{mg} / \mathrm{ml}$ of blood. The activity of CAT, SOD enzymes value was determined in erythrocytes treated and untreated by Pd (II) complexes in patients and control samples using spectrophotometric methods. All absorbance measurements were performed with a UV/Vis Spectrometer Lambda 14P (Perkin Elmer, USA).

\section{Catalase activity}

Catalase activity in erythrocytes was determined according to the spectrophotometric procedure by Beers and Sizer (1952) [25] and calculated as Bergmeyer units (BU/g Hb). CAT activity was measured at $25^{\circ} \mathrm{C}$ by recording $\mathrm{H}_{2} \mathrm{O}_{2}$ decomposition at $240 \mathrm{~nm}$ with a spectrometer (UV/VIS Spectrometer Lambda 14P, Perkin Elmer, USA). One Bergmeyer unit (BU) of this activity is defined as the amount of enzyme decomposing $1 \mathrm{~g}$ of $\mathrm{H}_{2} \mathrm{O}_{2}$ per min [26].

\section{Superoxide dismutase activity}

Superoxide dismutase activity in erythrocytes was measured by the method of Misra and Fridovich (1972) [27] and expressed in adrenaline units [U/g Hb/100ml]. SOD activity was determined at $37^{\circ} \mathrm{C}$ by the absorbance increase at $480 \mathrm{~nm}$ with a spectrometer (UV/VIS Spectrometer Lambda 14P, Perkin Elmer, USA) followed by the autooxidation of adrenaline inhibited by $\mathrm{CuZn-SOD}$. One unit of SOD activity is defined as the amount of enzyme inhibiting adrenaline autooxidation at 50\% [28].

\section{Statistical analysis}

The data point in this study was calculated for three separate experiments from each analyzed patient or control sample. The activity of enzymes was expressed as a mean value \pm standard deviation. Blinded replicate samples were used for quality control (QC). If no significant differences between variations were found, as assessed by the Snedecor-Fisher test, the differences between means were evaluated by applying the Student's t-test. Otherwise, the Cochran- 
Cox test was used. The data was analyzed using the STATISTICA (StatSoft, Tulsa, OK, USA) statistical package.

\section{RESULTS}

Tab. I. and II. show an antioxidant status in head and neck squamous cell carcinoma (HNSCC) patients and healthy subjects measured as the activity of catalase and superoxide dismutase. The mean activity of CAT as Bergmeyer units [BU/g Hb], SOD as adrenaline units $[\mathrm{U} / \mathrm{g} \mathrm{Hb} / 100 \mathrm{ml}]$. All the results were produced in triplicate.

Our data emphasizes that the addition of compounds Pd (II) leads to a statistically significant increase of enzyme activity as compared to samples without prior incubation of chemicals. The differences between the two groups (samples with incubation -1 and without incubation -2 with synthesized compounds) were calculated using a $\mathrm{t}$-test for dependent samples.

Tab. I. shows the mean CAT and SOD activity in the head and neck cancer group A (A1 - with prior incubation of blood sample with Pd (II) complex (a), (b), (c) and A2 - without prior incubation of blood sample with Pd (II) complex).

Tab. II. shows the mean CAT and SOD activity in the control group (B1 - with prior incubation of blood sample with Pd (II) complex (a), (b), (c) and B2 - without prior incubation of blood sample with Pd (II) complex).

Statistically significant results for the compound a and CAT enzyme were obtained for the following groups: A1/B1 and A2/B2 $(\mathrm{P}<0.001)$. For complex a and SOD enzymes significant results were received in the following groups: A1/A2, A2/B2 $(\mathrm{P}<0.01)$.

We obtained significant results for CAT enzymes after an application of complex $b$ for the following groups: A1/B1, A2/B2 ( $<<0.001)$. Significant results for SOD and complex b were achieved in the following groups: A1/A2 ( $<<0.001), \mathrm{B} 1 / \mathrm{B} 2(0.02), \mathrm{A} 1 / \mathrm{B} 2(\mathrm{P}=0.003)$.

Significant results after the use of complex c and CAT enzyme were obtained for the following groups: A1/A2, B1/B2 $(\mathrm{P}<0.001)$, $\mathrm{A} 1 / \mathrm{B} 1(\mathrm{P}=0.001), \mathrm{A} 2 / \mathrm{B} 2(\mathrm{P}=0.008)$. There are no statistically significant results for the SOD enzyme.

\section{DISCUSSION}

Free radicals, such as $\mathrm{O}_{2^{-}}$, $\mathrm{ROO}-, \mathrm{OH}$ - are molecules that contain an unpaired electron. They are produced in many physiological, as well as pathological processes. The reaction of hemoglobin autooxidation to methemoglobin that occurs in erythrocytes is an example of a physiological process. As a result of this reaction a superoxide radical anion is formed. Respiratory burst of neutrophils is another process that is natural and very important to our immune system. When this phenomenon occurs, neutrophils affected by chemotactic factors release $\mathrm{O}_{2}, \mathrm{OH}$ - and other reactive oxygen species (ROS), which enables many microorganisms to be removed $[29,30]$. Free radicals are also produced by the action of external factors on living cells, such as tobacco smoke, UV radiation and many others. The elevated level of reactive oxygen species is extremely harmful for living systems and causes damages in lipid membranes, proteins and DNA. The lipid damage occurs as a result of a non-enzymatic process called peroxidation. The final products of this reaction can easily react with the thiol group in proteins and amino acid residues. The consequence of this phenomenon is the impairment of protein function. It also modifies physical properties of cell membranes affecting the electron transport chain [26]. DNA is vulnerable to ROS as well. It causes DNA breakage which can lead to carcinogenesis.

Oxidative stress is believed to be one of many factors leading to conditions such as glaucoma and Parkinson's disease but also diabetes or atherosclerosis [31]. There are many studies that explain how oxidative stress contributes to a particular disease. For instance, an increased amount of ROS causes modifications in low-density lipoprotein (LDL) particles which stimulate the production of agents that promote modified LDL uptake by macrophages [32]. Living organisms have developed protection against ROS - an oxidative barrier which consists of many biologically active compounds and enzymes. The enzymatic line of organism defense is mainly built up of three enzymes: CAT, SOD, and glutathione peroxidase (GPx). Each of them has several isoformes by which they can completely fulfill their role. We are also protected by many naturally occurring compounds such as: vitamins, flavonoids, carotene, melatonin and many others. The antioxidative barrier is very important for the proper functioning of living systems and its absence indicates serious disorders. In their study Sakhi et al. (2009) proved a reduced effectiveness of the antioxidative barrier in head and neck squamous cell carcinoma patients [33]. Our paper confirms these results: the patients in the study group (A) had reduced catalase and superoxide dismutase levels as compared to the control group (B). A reduced activity of the antioxidative barrier was also proven in other diseases. Misiak et al. (2014) showed a decreased activity of SOD, CAT and GPx in patients with lung cancer [34]. Radical tumor resection caused an increased activity of GPx and CAT, as well as total antioxidative status. On the other hand, Malinowska et al. (2015) proved an augmented activity of SOD and GPx in patients with colorectal cancer [35]. Other research conducted by Tas et al. proved that patients with breast cancer have increased SOD and GPx levels, as well as malondialdehyde (MDA) level, which is known as a product of lipid peroxidation. What is interesting, they have also demonstrated a decreased CAT level [28]. It is interpreted that the activity of antioxidative enzymes strictly depends on the type of cancer and its stage.

The most popular example of using these elements in anticancer therapies is cisplatin. Despite its effectiveness and well-established position in oncology, cisplatin has severe side effects that force searching for new potential drugs. Pyrazole formation in newly synthesized compounds is aimed at supporting the antioxidant barrier. It is an interesting research object because of its properties as well as the fact that it is widespread in living organisms. There are also many studies that describe the pyrazole ring as a part of complex compounds in which elements such as copper (II), palladium (II), platinum (II) are the central atoms. An example of newly synthesized complex compounds containing the abovementioned 
elements is a study carried out by Kupcewicz et al. (2013) [23]. In their paper on copper (II) complexes they used derivatives of pyrazole as ligands. The authors showed that some of their compounds increased the activity of SOD, CAT and GPx. Budzisz et al. obtained a series of compounds containing palladium (II) and platinum (II). Some of them exhibit a high cytotoxicity towards the human leukemia cell line (HL-60) and B-cell precursor leukemia cell line (NALM-6) and low cytotoxicity towards non-cancer human umbilical vein endothelial cells (HUVEC) [36].
In our work we studied the activity of three newly synthesized palladium (II) complexes of substituted pyrazole containing ligands. We showed that these compounds increase the activity of antioxidant enzymes in patients with HNSCC and the healthy ones. It seems that we obtained the most promising result regarding compound $\mathrm{c}$ as we observed the most significant change in the activity of enzymes. Further studies on these novel compounds will be conducted, however, this preliminary data indicates a great potential of palladium (II) complexes in HNSCC therapy.

\section{ACKNOWLEDGEMENTS}

This work was supported by the Medical University in Lodz with a fund number 503/5-061-03/503-51-001-17.

\section{REFERENCES}

1. Lippert B.: Cisplatin. Chemistry and Biochemistry of a Leading Anticancer Drug. VHCA \& Wileyn VCH., Zurich 1999.

2. Dasari S., Tchounwou P.B.: Cisplatin in cancer therapy: molecular mechanisms of action. Eur J Pharmacol., 2014; 740: 364-378.

3. Akdi K., Vilaplana R.A., Kamah S., Navarro J.A., Salas J.M., Gonzalez-Vilchez F Study of the biological effects and DNA damage exerted by a new dipalladium-Hmtpo complex on human cancer cells. J Inorg Biochem., 2002; 90(1-2): 51-60.

4. Rocha C.R.R., Silva M.M., Quinet A., Cabral-Neto J.B., Menck C.F.M.: DNA repair pathways and cisplatin resistance: an intimate relationship. Clinics (Sao Paulo)., 2018; 73(Suppl 1): e478s.

5. Hartmann I.T., Lipp H.P.: Toxicity of platinum compounds. Expert Opin Pharmacother., 2003; 4: 889-901.

6. Choi Y.M., Kim H.K., Shim W., Anwar M.A., Kwon J.W., Kwon H.K. et al.: Mechanism of Cisplatin-Induced Cytotoxicity Is Correlated to Impaired Metabolism Due to Mitochondrial ROS Generation. PLoS One., 2015; 10: e0135083.

7. Kosmider B., Wyszynska K., Janik- Spiechowicz E., Osiecka R., Zyner E., Ochoc ki J. et al.: Evaluation of the genotoxicity of cis-bis(3-aminoflavone) dichloroplatinum (II) in comparison with cis-DDP. Mutat Res., 2015; 558: 93-110.

8. Oun R., Moussa Y.E., Wheate N.J.: The side effects of platinum-based chemotherapy drugs: a review for chemists. Dalton Trans., 2018; 47: 6645-6653.

9. Ndagi U., Mhlongo N., Soliman M.E.: Metal complexes in cancer therapy - an update from drug design perspective. Drug Des Devel Ther., 2017; 11: 599-616.

10. Daghriri H., Huq F., Beale P.: Studies on activities, cell up take and DNA binding of four multinuclear complexes of the form: [ $[\operatorname{trans}-\mathrm{PtCl}(\mathrm{NH}(3))(2)](2)$ mu-[trans- $\mathrm{Pd}(\mathrm{NH}(3))(2)-(\mathrm{H}(2) \mathrm{N}(\mathrm{CH}(2))(\mathrm{n}) \mathrm{NH}(2))(2)]] \mathrm{Cl}(4)$ where $\mathrm{n}=4-7$. J Inorg Biochem., 2004; 98: 1722-1733.

11. Kovala-Demertzi D., Domopoulou A., Demertsiz M.A., Valle G., Papageorgiu A.: Palladium (II) complexes of 2-acetylpyridine N (4)-methyl, N (4)-ethyl and $\mathrm{N}$ (4)-phenyl-thiosemicarbazones. Crystal structure of chloro (2-acetylpyridine $\mathrm{N}(4)$-methylthiosemicarbazonato) palladium (II). Synthesis, spectral studies, in vitro and in vivo antitumour activity. J Inorg Biochem., 1997; 68: 147-155.

12. Quiroga A.G., Perez J.M., Montero E.I., West D.X., Alonso C., Navarro-Ranninger C.: Synthesis and characterization of Pd (II) and Pt (II) complexes of p-izopropylobenzen $\mathrm{N}$-protected thiosemicarbazones. Cytotoxic activity against ras-transformed cells. J Inorg Biochem., 1999; 75: 293-301.

13. Matesanz A.I., Perez J.M., Navarro P., Moreno J.M., Colacio E., Souza P.: Synthesis and characterization of novel palladium (II) complexes of bis(thiosemicarbazone). Structure, cytotoxic activity and DNA binding of pd (II)-benzyl bis(thiosemicarbazonate). J Inorg Biochem., 1999; 76: 29-37.

14. Zhu M., Cui X., Zhang S., Liu L., Han Z., Gao E.: The structures, cytotoxicity, apoptosis and molecular docking controlled by the aliphatic chain of palladium (II) complexes. J Inorg Biochem., 2016; 157: 34-45.

15. Montoya V., Pons J., Solans X., Font-Bardia M., Ros J.: Synthesis, spectroscopic properties and structural characterization of Pd (II) and Pt (II) complexes with 1,3,5-pyrazole derived ligands. Rotation around the metal-N bond. Inorg Chim Acta., 2005; 358: 2312-2318.
16. Naim M.J., Alam O., Nawaz F., Alam Md. J., Alam P.: Current status of pyrazole and its biological activities. J Pharm Bioallied Sci., 2016; 8: 2-17.

17. Zejc A., Gorczyca M.: Drug chemistry. Wydawnictwo Lekarskie PZWL, Warszawa 2002.

18. Kucukguzel Ş.G., Şenkardeș S.: Recent advances in bioactive pyrazoles. Eur J Med Chem., 2015; 97: 786-815.

19. Mohs R.C., Greig N.H.: Drug discovery and development: Role of basic biological research. Alzheimers Dement (N Y)., 2017; 3(4): 651-657.

20. Schepetkin I., Potapov A., Khlebnikov A., Korotkova E., Lukina A., Malovichko G. et al.: Decomposition of reactive oxygen species by copper (II) bis (1-pyrazoly) methane complexes. J Biol Inorg Chem., 2006; 11(4): 499-513.

21. Ciolkowski M., Paneth P., Lorenz I.P., Mayer P., Rozalski M., Krajewska U. et al.: Tautomeric forms study of $1 \mathrm{H}$-(2'-pyridyl)-3-methyl-5-hydroxypyrazole and 1H-(2'-pyridyl)-3-phenyl-5-hydroxypyrazole. Synthesis, structure, and cytotoxic activity of their complexes with palladium (II) ions. J Enzyme Inhib Med Chem., 2009; 24: 1257-1268.

22. Sobiesiak M., Lorenz I.P., Mayer P., Woźniczka M., Kufelnicki A., Krajewska U. et al.: Synthesis, X-ray structure and cytotoxic effect of nickel (II) complexes with pyrazole ligands. Eur J Med Chem., 2011; 46: 5917-5926.

23. Kupcewicz B., Sobiesiak K., Malinowska K., Koprowska K., Czyz M., Keppler B. et al.: Copper (II) complexes with derivatives of pyrazole as potential antioxidant enzyme mimics. Med Chem Res., 2013; 22: 2395-2402.

24. Grazul M., Besic-Gyenge E., Maake C., Ciolkowski M., Czyz M., Sigel R.K. et al.: Synthesis, physico-chemical properties and biological analysis of newly obtained copper (II) complexes with pyrazole derivatives. J Inorg Biochem., 2014; 135: 68-76.

25. Beers R.F. Jr, Sizer I.W.: A spectrophotometric method for measuring the breakdown of hydrogen peroxide by catalase. J Biol Chem., 1952; 195(1): 133-140.

26. Birben E., Sahiner U.M., Sackesen C., Erzurum S., Kalayci O.: Oxidative stress and antioxidant defense. World Allergy Organ., 2012; 5(1): 9-19.

27. Misra H.P., Fridovich I.: The role of superoxide anion in the autoxidation of epinephrine and a simple assay for superoxide dismutase. J Biol Chem., 1972; 247: 3170-3175.

28. Tas F., Hansel H., Belce A., Ilvan S., Argon A., Camlica C. et al.: Oxidative stress in breast cancer. Medical Oncology., 2005; 22: 11-15.

29. Babior B.M.: Phagocytes and oxidative stress. Am J Med., 2000; 109(1): 33-44.

30. Zhaoa X., Drlicab K.: Reactive oxygen species and the bacterial response to lethal stress. Curr Opin Microbiol., 2014; 21(1-6).

31. Malinowska K., Majsterek I., Glinka Ł., Modranka R.: The role and use of antioxidants medicine. Pol J Cosmetol., 2015; 18: 88-95.

32. Singh U., Jialal I.: Oxidative stress and atherosclerosis. Pathophysiology., 2006; 13(3): 129-142.

33. Sakhi A.K., Russnes K.M., Thoresen M., Bastani N.E., Karlsen A., Smeland S. et al.: Pre-radiotherapy plasma carotenoids and markers of oxidative stress are associated with survival in head and neck squamous cell carcinoma patients: a prospective study. BMC Cancer., 2009; 9: 458. 
34. Misiak P., Rzepkowska-Misiak B., Wcisło S., Dziwińska K., Malinowska K., Majsterek I.: Evaluation of the impact of radical tumor resection in lung cancer patients on the activity of selected antioxidant enzymes. Kardiochir Torakochirurgia Pol., 2014; 11: 414-420.
35. Malinowska K., Mik M., Dziki Ł., Dziki A., Majsterek I.: Evaluation of antioxidant defense in patients with colorectal carcinoma. Pol Przegl Chir, 2015; 87(7):357-361.

36. Budzisz E., Krajewska U.. Rozalski M., Szulawska A., Czyz M., Nawrot B.: Biological evaluation of novel Pt (II) and Pd (II) complexes with pyrazole-containing ligands. Eur J Pharmacol., 2004; 502(1-2): 59-65.

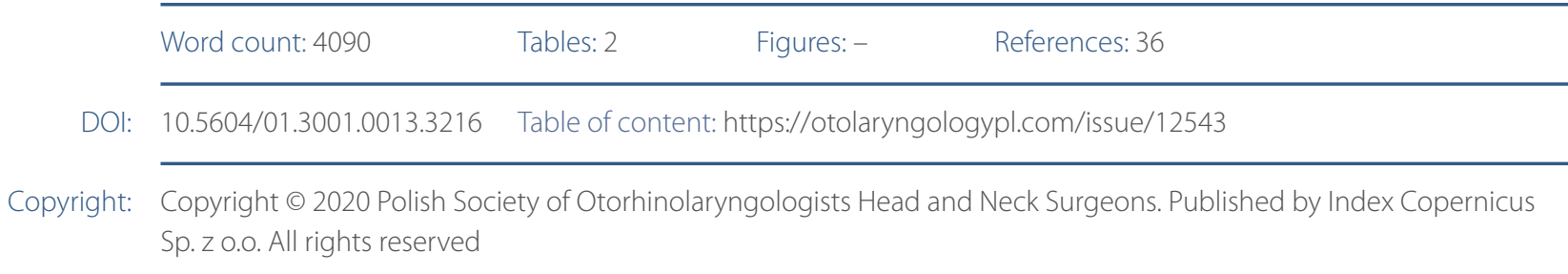

Competing interests: The authors declare that they have no competing interests.

2 The content of the journal "Polish Society of Otorhinolaryngologists Head and Neck Surgeons" is circulated on the basis of the Open Access which means free and limitless access to scientific data.

Corresponding author:

Cite this article as:

This material is available under the Creative Commons - Attribution 4.0 GB. The full terms of this license are available on: http://creativecommons.org/licenses/by-nc-sa/4.0/legalcode

Alicja Nowak-Zduńczyk; University of Business and Health Sciences in Lodz; Piotrkowska Street 278, 90-361 Lodz, Poland; E-mail:alicjanowak87@wp.pl

Malinowska K., Kaczmarczyk D., Zajdel R., Merecz-Sadowska A., Olszewski J., Majczyk M., Nowak-Zdunczyk A., ZielinskaBlizniewska H.: Antioxidative assessment of new trans-palladium (II) complexes in head and neck cancer; Otolaryngol Pol 2020; 74 (1): 23-28 